\title{
Aydın'da İkinci Ürün Pamuk Ekim Alanlarında Sokucu-Emicilerin Popülasyon Değişimlerinin Saptanması
}

\author{
*Savaş KILIÇ1 İbrahim GENÇSOYLU² \\ ${ }^{1}$ Tarım Kredi Kooperatifi, Çakırbeyli, Aydın \\ ${ }^{2}$ Adnan Menderes Üniversitesi, Ziraat Fakültesi, Bitki Koruma Bölümü, Aydın \\ *Sorumlu yazar e-posta (Corresponding author e-mail): savaskilic09@gmail.com
}

\begin{abstract}
Öz
Çalışma, 2012-2013 yıllarında Aydın Ili'nde ikinci ürün pamuk çeşitlerinde sokucu-emicilerin popülasyon değişimlerini saptamak amacıyla yapılımıştır. Çalışma, ikinci ürün olarak ekimin yoğun olarak yapıldığı Söke ilçesinde yapılımıştır. Çalışmada tüylü çeşit olan, May 373 , az tüylü Flash ve tüysüz olan Glora çeşitlerinde yapıImıştır. Çalışma sonucunda, A.gossypii, 2012 yılında en yüksek popülasyon yoğunluğuna 5.54 adet/yaprak ile, 2013 yılında ise 14.47 adet/yaprak ile May 373 çeşidinde ulaşmıştır. Bemisia tabaci ise en yüksek yoğunluğa 2012 yılında 1.08 adet/yaprak ile May 373 pamuk çeşidinde ulaşırken, 2013 yılında 0.42 adet/yaprak ile Flash çeşidinde ulaşmıştır. Tetranychus spp. ise 2012 yılında en yüksek yoğunluğa 9.59 adet/yaprak ile, 2013 yılında ise 8.65 adet/yaprak ile May 373 çeşidinde ulaşmıştır. Frankliniella spp. ise 2012 yılında en yüksek yoğunluğa 28 adet/çiçek ile, 2013 yılında ise 28 adet/çiçek ile Flash çeşidinde görülmüştür. Asymetrasca decedens ve Empoasca decipiens ve Thrips tabaci ise düşük seviyelerde görülmüştür. Sonuç olarak, zararlıların popülasyon yoğunluğunun değişmesinde tüy miktarının önemli olduğu belirlenmiş olup, tüylülük miktarının zararılıarla mücadelede kullanılabileceği saptanmıştır.
\end{abstract}

Anahtar Kelimeler: Pamuk, ikinci ürün, sokucu-emiciler

\section{Determinate the Population Dynamics of Sucking-Piercing Pest in Cotton Planted as Second Crop in Aydın}

\begin{abstract}
The study was conducted to evaluate the population dynamics of piercing-sucking pests in cotton planted as a second crop in Aydın, Söke. In the study May 373 (high hair), Flash (low hair), and Gloria (no hair) were used. At the end of study A. gossypii was reached to highest amount with 5.54 and 14.47 per leaf in 2012 and 2013 in May 373. B. tabaci was reached to 1.08 per leaf in May 373 in 2012 and 0.42 in flash in 2013. Tetranychus spp. was reached to 9.59 and 8.65 per leaf in May 373 in 2012 and 2013. On the other hand, Frankliniella spp. was reached to 28 per flower in both years in Flsah. Asymetrasca decedens+Empoasca decipiens and Thrips tabaci were observed low amount. As a result, hair on leaf affected the amount of piercing-sucking pests in cotton and this can be used for the management against the insects.
\end{abstract}

Keywords: Cotton, second crop, piercing-sucking

\section{Giriş}

A ydın ili pamuk üretiminin büyük bir kısmını 328.800 dekar alanda 162.670 ton ile söke ilçesi sağlamaktadır (Anonim 2013). Son yıllarda ülkemizde normal pamuk üretiminin yanında ikinci ürün pamuk üretiminin gittikçe yaygınlaştığı görülmektedir. Bölgede pamuk verimini ve lif kalite özelliklerini üzerinde etkileyen potansiyel bazı zararlılar bulunmaktadır (Gençsoylu 2001). Zararlılar ile mücadelede önemli bir yere sahip olan kültürel yöntemler içinde yer alan ekim zamanı, zararlı yoğunluğunu önemli derecede etkilemektedir. Ülkemizde Atakan ve Gençer (2008) Çukurova Bölgesi'nde geç ekim yapılan alanlarda $F$. intonsa'nın daha yoğun olduğunu bildirmiştir. Slosser et al. (1992), Texas' ta 3 farklı ekim tarihlerinin $A$. gossypii'nin geç haziranda yapılan ekimlerde daha yoğun olarak saptamışlardır. Bemisia tabaci'nin yoğunluğunun ise geç nisan ve geç mayıs ayında, Slosser (1993) ise T. tabaci yoğunluğunun nisan 
sonlarında, Empoasca spp. mayıs sonunda, Anthonomus'ların geç ekimlerde, $A$. gossypii'nin ise haziran sonuna doğru yapılan ekimlerde daha yoğun olduğunu saptamıştır. Parajulee et al. (2006)'de T. tabaci ve Empoasca spp. yoğunluklarının geç ekilen alanlarda daha yoğun olduğunu ifade etmektedirler. Diğer taraftan Cranmer (2004) ise Lygus yoğunluğunun erken ekimlerde daha fazla olduğunu ifade etmiştir. Zararlıarın yoğunluğu üzerinde ekim tarihlerinin etkisinin yanında tüy miktarı da etkili olmaktadır. Nitekim, Salim ve ark. (2013), Sudan'da yoğun tüğ miktarı olan Acala çeşitinde daha fazla B. tabaci yoğunluğu rastlanıldığını belirtmişlerdir. Bu çalışmada ikinci ürün olarak yaygın olarak ekimi yapılan ve tüy miktarı faklı olan 3 çeşit, Flash, Gloria ve May 373 çeşidinde sokucu-emicilerin populasyon değişimleri saptanmıştır. Bu çalışma, Aydın ilinde ikinci ürün olarak ekilen pamuk alanlarında sokucu-emici böceklerin populasyon değişimlerini saptamak amacıyla yapılmıştır.

\section{Materyal ve Yöntem}

Söke ilçesinde ikinci ürün olarak kullanılan Flash, May 373 ve Gloria çeşitlerinde yapılmıştır. Deneme, tesadüf blokları deneme desenine göre yapılmış, her bir blok 8 sıralı, 9 m uzunluğunda ve 20 m genişliğinde, sıra arası mesafe $70 \mathrm{~cm}$ ve sıra üzeri $20-25 \mathrm{~cm}$ 'dir. Bloklar ve tekerrürler arasında kenar tesiri için 3 m mesafe bırakılmıştır. Pamuk ekimi, 2012 yılında 12 Haziran, 2013 yılında 6 Haziran tarihlerinde havalı mibzerle yapılmıştır. Tüm kültürel uygulamalar (gübreleme, sulama v.b) üretici koşullarına göre yapılmıştır. 2013 yılında yaprakbiti popülasyonun daki aşırı artışın denemeye zarar vereceği düşünüldüğü için 26.08.2013 tarihinde Acetamiprid \%20 etkili maddeli bir insektisit $30 \mathrm{gr} / \mathrm{da}$ dozunda tüm parsellere uygulanmıştır.

Uygulama alanlarında zararlıların popülasyon sayımları, pamuk tohumu çimlenip 2 yapraklı döneme geldiğinde başlanmış, 6 yapraklı oluncaya kadar tüm yapraklar daha sonra hasat sonuna kadar her bitkiden 6 yaprak ( 2 alt, 2 orta, 2 üstten olacak şekilde) kontrol edilmiş ve üzerinde var olan zararlılar haftalık olarak kaydedilmiştir. Zararlıların sayımı ise 2012 yılında 24 Haziran'da başlanmış 04 Ekim' de sona ererken, 2013 yılında 15 Haziran' da başlanmış

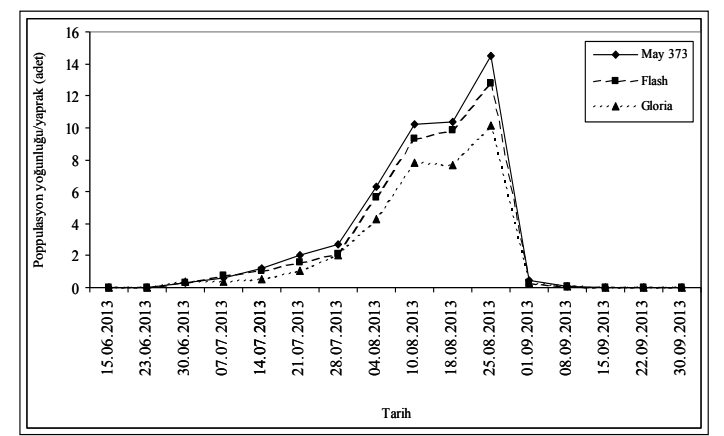

Şekil 1. 2012 ve 2013 yılı Aphis gossypił'nin farkli pamuk çeşitlerinin ekili olduğu alanlardaki popülasyon değişimleri

Figure 1. Population dynamics of Aphis gossypii on areas where different cotton varieties were planted in 2012 and 2013
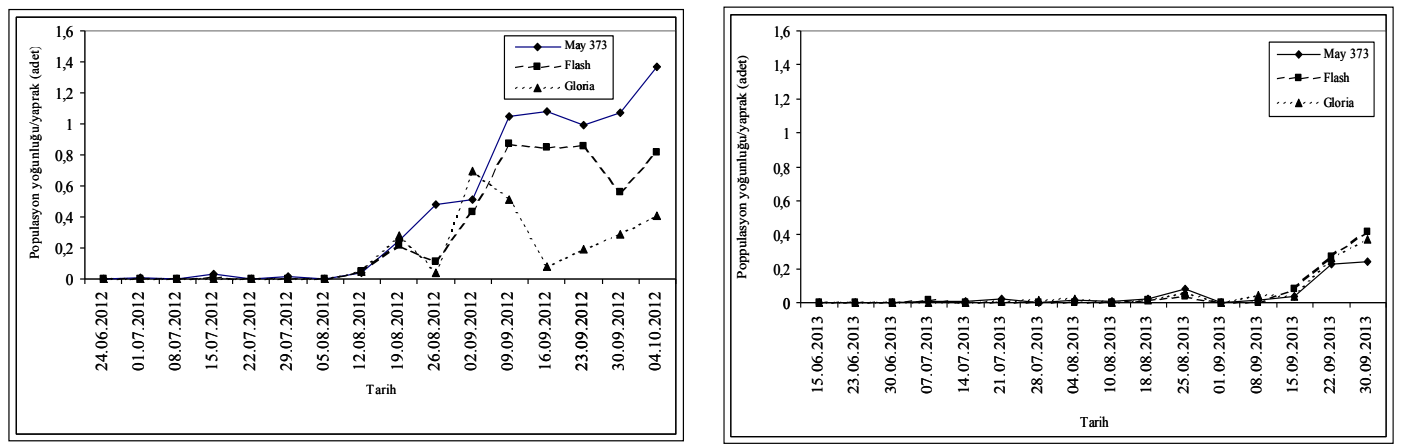

Şekil 2. 2012 ve 2013 yılında Bemisia tabaci' nin farklı pamuk çeşitlerinin ekili olduğu alanlardaki popülasyon değişimi

Figure 2. Population dynamics of Bemisia tabaci on areas where different cotton varieties were planted in 2012 and 2013 
30 Eylül' de sona ermiştir. Her uygulama için her parselden 10 bitki, 3 tekerrürden toplam 30 bitkide kontroller yapılmıştır. Empoasca spp., $A$. gossypii, B. tabaci için yaprak başına, Frankliniella spp. için ise her bir parselden 10 bitki sayılacak çiçek başına birey sayısı verilmiştir. Asymetrasca decedens Paoli ve Empoasca decipiens Paoli beraber sayılmış ve Empoasca spp. olarak, F. occidentalis ve F.intonsa ayrı ayrı verilmiştir.

\section{Bulgular ve Tartışma}

\section{Aphis gossypii Glover'nin Popülasyon Değişimi}

2012 ve 2013 yılında A. gossypii' nin farklı çeşitlerdeki popülasyon değişimi Şekil 1'de verilmiştir. 2012 yılında zararlı popülasyon yoğunluğu 01.07.2012 tarihinden itibaren düşük düşük yoğunlukta görülmeye başlanmış, bu tarihten itibaren yoğunluk az da olsa düşük yoğunlukta devam etmiştir. Zararlının yoğunluğu 08.07.2012'de artmaya başlamış, 22.07.2012 tarihinde en yüksek seviyeye ulaşmıştır. Bu tarihte en yüksek yoğunluk 9.59 adet/yaprak ile May 373 çeşidinde olurken, onu 4.12 adet/yaprak ile Flash ve 3.12 adet/yaprak ile Gloria çeşidi izlemiştir. Daha sonra popülasyon yoğunluğu hızlı bir düşüşe geçerek 09.09.2012 tarihine kadar az miktarda da olsa devam etmiş ve 09.09.2012 tarihinden sonra da zararlı popülasyonuna rastlanılmamıştır.

2013 yılında ise, zararlı yoğunluğu 2012 tarihinde olduğu gibi ilk dönemlerde değil sonraki dönemlerde rastlanıımıştır. Sayımlar, 15.06.2013 tarihinde başlanmış 23.06.2013 tarihine kadar herhangi bir zararlı popülasyona rastlanmamıştır. 23.06.2013 tarihinden 04.08.2013 tarihine kadar ise zararlı popülasyon yoğunluğu artarak devam etmiş olup, 04.08.2013 tarihinden 25.08.2013 tarihine kadar ise hızı ı bir artış göstermiştir. 25.08.2013 tarihinde tüm çeşitlerde zararlı yoğunluğu en üst seviyeye ulaşmış ve May 373 çeşitinde 14.47 adet/yaprak, Flash çeşitinde 12.75 adet/yaprak ve Gloria çeşidinde 10.12 adet/yaprak olarak en üst seviyeye ulaşmıştır. 25.08.2013 tarihinden itibaren zararlı popülasyonu hızlı düşüşe geçmiş ve 15.09.2013 tarihinden itibaren ise deneme alanlarında zararlı popülasyonuna rastlanılmamıştır. Sonuçta, $A$. gossypii, 2012 yılında en yüksek popülasyon yoğunluğuna 5.54 adet/yaprak ile, 2013 yılında ise 14.47 adet/yaprak ile May 373 çeşidinde ulaşmıştır. 2013 yılında yüksek olmasında iklim faktörlerinin etken olduğu düşünülmektedir. Yoğunuğun normal ekime göre oldukça yüksek olduğu görülmektedir.

\section{Bemisia tabaci Gennadius' nin Popülasyon Değişimi}

2012 ve 2013 yılında B. tabaci'nin farklı pamuk çeşitlerindeki popülasyon değişimi Şekil 2' de verilmiştir. 2012 yılında zararlı popülasyon yoğunluğu 01.07.2012 tarihinden itibaren düşük yoğunlukta görülmeye başlanmış, bu tarihten sonra popülasyon yoğunluğu azda olsa görülmeye devam etmiştir. 12.08.2012 tarihinden itibaren yoğunluk artmaya başlamış ve en yüksek yoğunluk, 16.09.2012 tarihinde 1.08 adet/yaprak ile May 373 pamuk çeşidinde, onu 0.85 adet/yaprak ile Flash çeşidi ve 0.51 adet/yaprak ile Gloria çeşidi izlemiştir. Bu tarihten itibaren zararlı yoğunluğu en son sayımın yapıldığı 04.10.2012 tarihine kadar tekrar artarak devam etmiştir.

2013 yllında ise, 15.06.2013'den 30.06.2013 tarihine kadar herhangi bir yoğunluğa rastlanılmamıştır. $\quad 07.07 .2013$ tarihinden 08.09.2013 tarihine kadar zararlı yoğunluklarında dönemsel olarak artışlar, azalışlar meydana geldiği gözlenilmişse de bu tarihten itibaren popülasyon yoğunlukları çok hızlı bir şekilde artmaya devam etmiş ve son sayımın yapıldığı 30.09.2013 tarihinde en yüksek yoğunluk 0.42 adet/yaprak ile Flash çeşidinde, 0.37 adet/yaprak ile Gloria çeşidinde ve 0.24 adet/yaprak ile May 373 çeşidinde olmuştur. Sonuçta, Bemisia tabaci ise en yüksek yoğunluğa 2012 yılında 1.08 adet/yaprak ile May 373 pamuk çeşidinde ulaşırken, 2013 yılında 0.42 adet/yaprak ile Flash çeşidinde ulaşmıştır. Zararlı yoğunluğunun düşük seviye olmasından dolayı tüy miktarının bir etkisi görülmese de normal üretimde görülen yoğunluk ile ikici üretim arasında önemli bir fark görülmemiştir.

\section{Asymetrasca decedens ve Empoasca decipiens Paoli' nin Popülasyon Değişimi}

Empoasca spp. nin 2012 ve 2013 yilında farklı pamuk çeşitlerindeki popülasyon değişimi Şekil 3' de görülmektedir. 2012 yılında zararının popülasyon yoğunluğu 01.07.2012 tarihinden itibaren örneklenmeye başlanmıştır. Popülasyon yoğunluğu ağustos ayının sonuna 

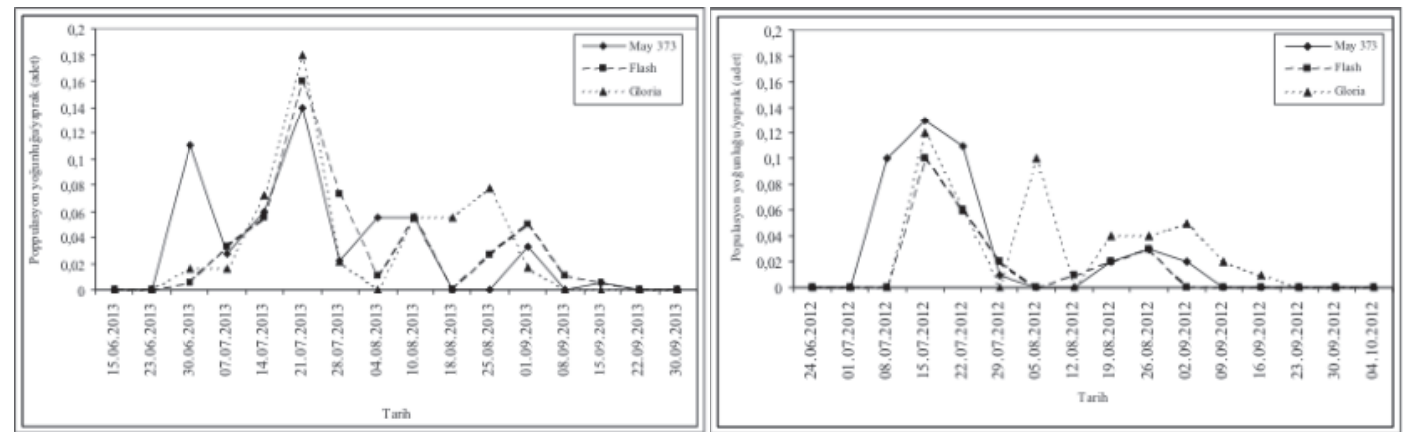

Şekil 3. 2012 ve 2013 yılında Empoasca spp.'nin farklı pamuk çeşitlerinin ekili olduğu alanlardaki popülasyon değişimi

Figure 3. Population dynamics of Bemisia tabaci on areas where different cotton varieties were planted in 2012 and 2013

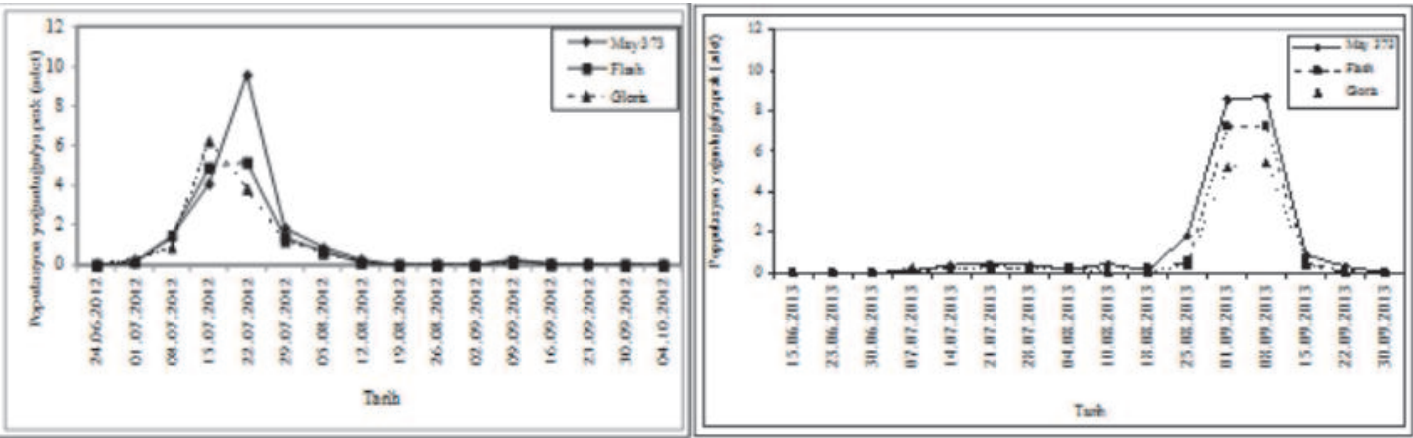

Şekil 4.2012 ve 2013 yılında Tetranychus spp.'nin farklı pamuk çeşitlerinin ekili olduğu alanlardaki popülasyon değişimi

Figure 4. Population dynamics of Tetranychus spp. on areas where different cotton varieties were planted in 2012 and 2013

kadar devam etmiştir. 01.07.2012 tarihinde parsellerde ilk sayımlara başlanılmış, 15.07.2012 tarihinde en yüksek seviyeye ulaşmış ve zararlı yoğunluğu 0.13 adet/yaprak ile en fazla May 373 çeşidinde, daha sonra 0.12 adet/yaprak ile Gloria çeşidinde ve 0.10 adet/yaprak ile Flash çeşidinde görülmüştür. 29.07.2012 tarihinde zararlı popülasyon miktarları oldukça azalmışsa da, 05.08.2012 tarihinde Gloria çeşidinin bulunduğu parselde aniden artış gösterip 0.10 adet/yaprak seviyesine ulaşmış 12.08.2012' de dalgalı bir şekilde seyretmiş ve ağustos ayının sonunda tekrar artış gözlenmiş ve eylül ayının ilk haftasından itibaren azalarak eylül sonuna kadar devam etmiştir. 2013 yılında ise zararlının yoğunluğu ilk dönemden itibaren artmaya başlamış, 21.07.2013 tarihinde, 0.19 adet/yaprak ile Gloria çeşidinde, daha sonra 0.16 adet/yaprak ile Flash çeşidinde ve 0.14 adet/yaprak ile May 373 çeşidinde en yüksek seviyeye ulaşmış ve sonra azalmaya başlamıştır. Yoğunluk tekrar 10.08.2013 tarihinde 0.06 adet/yaprak miktarında tüm çeşitlerde ortalama aynı popülasyon yoğunluğuna ulaşmış olup, bu tarihten itibaren, çok küçük miktarlarda artış ve azalışlar gösterip, 22.09.2013 tarihine kadar parsellerde zararlıya rastlanılmıştır. Sonuçta, $A$. decedens ve $E$. decipiens çok düşük yoğunlukta görülmüş ve normal ekim yapılan zamandaki yoğunluktan çok da farklı olmadığı görülmüştür. Ancak, Sana et al. (1989), bazı pamuk çeşitlerindeki tüy miktarının zararlı yoğunluğu üzerinde etkili olduğunu bildirmiştir. Ancak, bu çalışmada yoğunluğun düşük olmasından dolayı tüylülüğün etkisi tam olarak bu zararlı üzerinde tespit edilememiştir.

Tetranychus spp.( Acar: Tetranychidae)' nin Popülasyon Değişimi

2012 ve 2013 yılında Tetranychus spp. nin farklı çeşitlerde popülasyon değişimi Şekil 4' de verilmiştir. 2012 yılında zararlı popülasyon yoğunluğu 01.07.2012 tarihinden itibaren düşük yoğunlukta görülmeye başlanmış, bu tarihten itibaren yoğunluk az da olsa düşük yoğunlukta devam etmiştir. Zararlının yoğunluğu 
08.07.2012'de artmaya başlamış, 22.07.2012 tarihinde en yüksek seviyeye ulaşmıştır.

$\mathrm{Bu}$ tarihte en yüksek yoğunluk 9.59 adet/yaprak ile May 373 çeşidinde olurken, onu 5.16 adet/yaprak ile Gloria ve 3.84 adet/yaprak ile Flash çeşidinde daha sonra popülasyon yoğunluğu 29.07.2012 tarihinden sonra çok düşük seviyede dönem sonuna kadar devam etmiştir.

2013 yılında yapılan zararlı popülasyon sayımları 15.06.2013 tarihinde başlanmış, 30.06.2013 tarihine kadar herhangi bir popülasyona rastlanılmamıştır. $\quad 07.07 .2013$
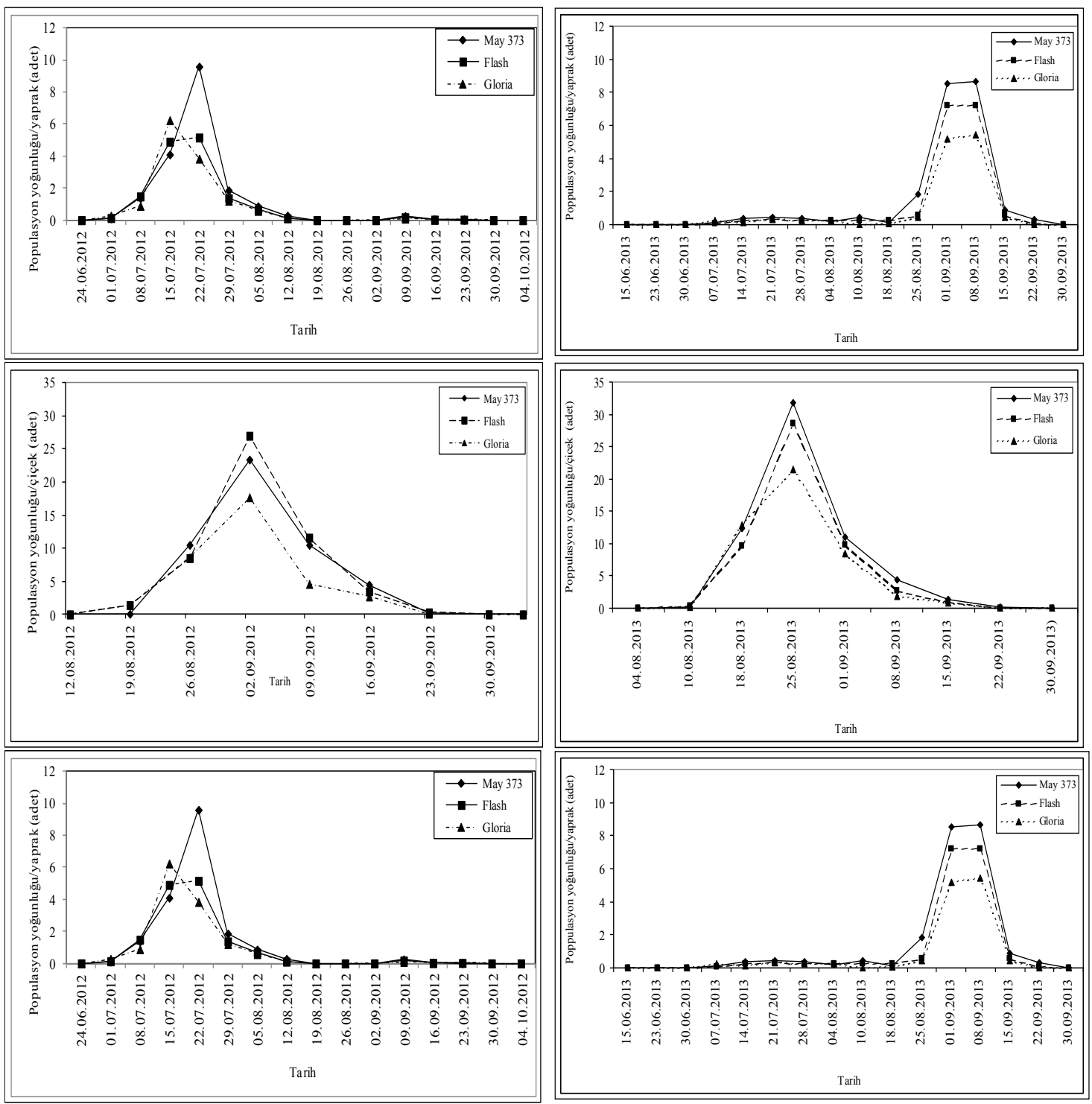

Şekil 5. 2012 ve 2013 yıllarında Frankliniella spp.'nin farklı pamuk çeşitlerinin ekili olduğu alanlardaki popülasyon değişimi

Figure 5. Population dynamics of Frankliniella spp. on areas where different cotton varieties were planted in 2012 and 2013 
Frankliniella spp. (Thys: Thripidae)' nin Popülasyon Değişimi

2012 ve 2013 yılında farklı pamuk çeşitlerindeki popülasyon değişimi Şekil 5 'de görülmektedir. Çalışmada çiçek thripsi olarak $F$. occidentalis ve F.intonsa saptanmıştır. F. intonsa daha yoğun görülmüş olup, çiçek başına olan thripsler birlikte değerlendirilmiş ve Frankliniella spp. olarak verilmiştir. 2012 yılında zararlının popülasyonu 19.08.2012 tarihinde artmaya başlayarak, 02.09.2012 tarihinde, 28 adet/çiçek ile Flash çeşidinde, 23 adet/çiçek May 373 ve 18 adet/çiçek Gloria çeşidinde en yüksek yoğunluğa ulaşmış, daha sonra popülasyon yoğunluğu azalarak 30.09.2012 tarihinden sonra popülasyona rastlanılmamıştır.

2013 yılında ise 19.08.2013 tarihinde artmaya başlayarak, 25.08.2013 tarihinde popülasyon en yüksek yoğunluğa ulaşmıştır. En yüksek yoğunluk 28 adet/çiçek ile Flash çeşidinde, 24 adet/çiçek ile May 373 çeşidinde ve daha sonra 17 adet/çiçek ile Gloria çeşidinde olmuştur. Sonuçta, Frankliniella spp. ise 2012 yılında en yüksek yoğunluğa 28 adet/çiçek ile, 2013 yllında ise 28 adet/çiçek ile Flash çeşidinde görülmüş ve normal ekime göre daha fazla yoğun olarak saptanmıştır. Parajulee et al. (2006), Atakan ve Gencer (2008)'de geç ekim yapılan alanlarda daha yoğun olduğunu belirtmiştir.

Thrips tabaci Lind (Thys: Thripidae)' nin Popülasyon Değişimi

2012 yılında popülasyon değişimi iki farklı tarihlerde en yüksek yoğunluğa ulaşmıştır. Zararlının popülasyon yoğunluğu 24.06.2012 tarihinde popülasyon yoğunluğu artışa geçmiş olup, 01.07.2012 tarihinde 0.05 adet/yaprak ile Gloria çeşidinde, 0.03 adet/yaprak ile Flash çeşidinde daha sonra 0.02 adet/yaprak ile May 373 çeşidinde en yüksek yoğunluğa ulaşmıştır. $\mathrm{Bu}$ tarihten sonra popülasyon yoğunluğunda dalgalanmalar görülmüş, 29.07.2012 tarihinde 0.04 adet/yaprak ile hem Flash çeşidinde hem de Gloria çeşidinde yoğunluk aynı miktarda olmuş, bunu 0.02 adet/yaprak ile May 373 çeşidi izlemiştir. Bu tarihten sonra yoğunluk azalmıştır.

2013 yılında ise popülasyon 15.06.2013 tarihinde ilk sayımlara başlanmış, bu tarihten sonra parseldeki popülasyon yoğunluğu artmaya başlamıştır. 06.07.2013 tarihinde 0.12 adet/yaprak ile Flash ve May 373 çeşidinde daha sonra 0.07 adet/yaprak ile Gloria çeşidinde en yüksek seviyeye ulaşmıştır ve bu tarihte yapılan sayımlardan sonra parsellerdeki popülasyon yoğunlukları hızla azalmaya başlamış ve 20.07.2013 tarihinden sonra ortamda rastlanılmamıştır. Sonuçta, T. tabaci yoğunluğu düşük seviye görülmüştür. Ancak Parajulee et al. (2006), Slosser (1993), yaptıkları çalışmada T. tabaci'nin erken ekilen pamuk alanlarında daha yoğun olduğunu, bunun nedene olarak ise iklim faktörlerinin etkili olacağı düşünülmektedir. Yoğunluğun düşük olmasından dolayı tüy miktarının etkisi gözlenememiştir.

\section{Sonuç}

Sonuç olarak, zararlıların popülasyon yoğunluğunun değişmesinde tüy miktarının önemli olduğu belirlenmiş olup, tüylülük miktarının zararlılarla mücadelede kullanılabileceği saptanmıştır.

\section{Teşekkür}

Çalışma, birinci yazarın Yüksek Lisans tezinin bir parçası olup, Adnan Menderes Üniversitesi Bilimsel Araştırma Projeleri Birimi tarafından desteklenmiştir.

\section{Kaynaklar}

Anonim 2013. Türkiye İstatistik Kurumu, http://www.tüik.gov.tr, $\quad$ (Erişim tarihi: 12.01.2013)

Atakan E., Gencer O., 2008. Influence of planting date on the relationship between populations of Franklieniella spp. flower thrips and predatory bug Orius niger in cotton. Journal Pest Science, 81: 123-133

Cranmer K., 2004. Influence of Planting Date and Cotton Cultivar on Lygus in the Texas High Plains and the Relationship between Boll Age Lygus hesperus Damage. Texas Technical Unıversity, Texas, $138 p$

Gençsoylu I., 2001. Büyük Menderes Havzası Pamuk Alanlarında Zararlılar ile Doğal Düşmanların Farklı Mücadele Programlarında Popülasyon Gelişimleri, Bunların Ürün Kalitesi ve Kantitesine Etkileri Üzerinde Araştırmalar. Adnan Menderes Üniversitesi, Fen Bilimleri Enstitüsü, Doktora Tezi, Aydın, 248s 
Hasnain M., Muhammad A., Sajid N., Kashif M., 2009. Morphological characters of different cotton cultivars in relation to resistance against Tetranychid mites. Pakistan Journal of Zoology, 41: 241-245

Parajulee M.N., Montondan R., Slosser J.E., 2006. Relay intercropping to enhance abundance of Insect predotors of cotton aphid in texas cotton. International Journal of Pest Manogement, 43: 227-232

Salim N., Abdalla M., Abdalla S., Ali I., 2013. Indidence of the white fly, Bemicia tabaci (Genn.) on two cotton varieties, pubescent and globrous grown under field conditions in Sudan. Persian Gulf Crop Protection, 2(3): 47-54
Sana E., Cabangbang R.P., Bader M., Manguiet I., 1989. Leaf hairiness and leafhopper resistance in selected cotton lines. Crop Science Society of the Philippines 14(1): 1-6

Slosser J.E., Parajulee M.I.N., Hendrix D.L., Henneberry T.V., Rummel D.R., 1992. Rleationship between Aphis gossypii (Homoptera: Aphididae) and sticky lint in cotton. Journal of Economic Entomology, 95.299-306

Slosser J.E., 1993. Influence of planting date and Insecticide treatment on insect pest abudance and damage in dryland cotton. Journal of Economic Entomology, 86: 1213-1222 